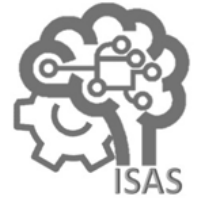

JOURNAL OF APPLIED CIVIL ENGINEERING AND INFRASTRUCTURE TECHNOLOGY (JACEIT)

Vol. 2 No. 2 (2021) 1-6

ISSN Media Elektronik: 2723-5378

\title{
Pengaruh Penambahan Plastik LDPE Pada Campuran Aspal Beton Lapis $\mathrm{AC}-\mathrm{BC}$
}

\author{
Hilda Nur Hidayati ${ }^{1}$, Mirza Ghulam Rifqi ${ }^{2}$, M. Shofi'ul Amin ${ }^{3}$ \\ ${ }^{1}$ Jurusan Teknik Sipil, Politeknik Negeri Banyuwangi \\ 2 Jurusan Teknik Sipil, Politeknik Negeri Banyuwangi \\ 1emai1: hildanur16@yahoo.co.id*, ${ }^{2} e m a i l: m i r z a @ p o l i w a n g i . a c . i d,{ }^{3}$ emai1: shofiul@poliwangi.ac.id
}

\begin{abstract}
Increased traffic volume growth has an impact on demand for the construction of pavement structures and the use of materials used. Therefore, we need a material that can help coat aggregate materials other than asphalt in order to reduce these effects, for example polymer or plastic materials. One effort that can be done is to modify the effect of adding Low Density Poly Ethylene (LDPE) plastic as an additive in AC-BC (Asphalt Concrete-Binder Course) asphalt mixture. The purpose of this study was to determine how the effect of the addition of Low Density Poly Ethylene (LDPE) type plastics as an added ingredient of AC-BC hot asphalt mixture on Marshall characteristics. Tests conducted include aggregate testing, asphalt testing, plastic testing, and Marshall testing. The design of the mixture is done by dry (dry process) using a variation of plastic content of $0 \%, 2 \%, 3 \%$, and $4 \%$ with each bitumen content of $4.5 \%, 5 \%, 5.5 \%, 6.0 \%$ and $6.5 \%$, the number of test specimens made is 75 test specimens. From the Marshall test results obtained KAO value of $6.5 \%$ with a variation in LDPE plastic content of $3 \%$. With a stability value of $1878.40 \mathrm{~kg}$, a flow value of $3.81 \mathrm{~mm}$, an MQ value of $472.5 \mathrm{~kg} / \mathrm{mm}$, a VFB / VFA value of $72.55 \%$, a VIM value of $4.29 \%$, and a VMA value of $17.74 \%$.
\end{abstract}

Keywords: LDPE Plastic, Marshall, Laston AC-BC, KAO, Dry Process

\begin{abstract}
Abstrak
Pertumbuhan volume lalu lintas yang meningkat memberikan dampak terhadap permintaan akan pembangunan struktur perkerasan jalan dan penggunaan material yang digunakan. Oleh karena itu, diperlukan suatu material yang dapat membantu melapisi bahan agregat selain aspal agar dapat mengurangi pengaruh tersebut, contohnya bahan polimer atau plastik. Salah satu upaya yang dapat dilakukan yaitu dengan dilakukan modifikasi pengaruh penambahan plastik Low Density Poly Ethylene (LDPE) sebagai bahan tambahan dalam campuran lapis aspal beton AC-BC (Asphalt Concrete-Binder Course). Tujuan dari penelitian ini adalah untuk mengetahui bagaimana pengaruh penambahan plastik jenis Low Density Poly Ethylene (LDPE) sebagai bahan tambah campuran beraspal panas AC-BC terhadap karakteristik Marshall. Pengujian yang dilakukan antara lain pengujian agregat, pengujian aspal, pengujian plastik, dan pengujian Marshall. Perancangan campuran dilakukan dengan cara kering (dry process) menggunakan variasi kadar plastik sebesar $0 \%, 2 \%, 3 \%$, dan 4\% dengan masing-masing kadar aspal yaitu $4,5 \%, 5 \%, 5,5 \%, 6,0 \%$, dan 6,5\%, jumlah benda uji yang dibuat yaitu 75 benda uji. Dari hasil uji Marshall diperoleh nilai KAO sebesar 6,5\% dengan variasi kadar plastik LDPE 3\%. Dengan nilai stabilitas sebesar 1878,40 $\mathrm{kg}$, nilai flow sebesar 3,81 mm, nilai MQ sebesar 472,5 kg/mm, nilai VFB/VFA sebesar 72,55 \%, nilai VIM sebesar 4,29\%, dan nilai VMA sebesar $17,74 \%$.
\end{abstract}

Kata kunci: Plastik LDPE, Marshall, Laston AC-BC, KAO, Dry Process

Diterima Redaksi : 04-08-2020 | Selesai Revisi : 29-09-2021 | Diterbitkan Online : 01-12-2021 


\section{Pendahuluan}

Aspal merupakan salah satu material yang digunakan Bahan yang digunakan dalam penelitian terlebih dahulu sebagai bahan pembuatan kontruksi jalan raya. Aspal dilakukan pengujian, agar memenuhi persyaratan yang sebagai bahan pengikat pada perkerasan lentur sangat telah ditetapkan. Pengujian yang dilakukan meliputi terpengaruh terhadap cuaca, terutama curah hujan. pengujian agregat kasar, pengujian agregat halus, Curah hujan yang sangat tinggi dapat mempercepat pengujian pasir pantai, pengujian bahan pengisi (filler), kerusakan jalan dan pelapukan agregat pada konstruksi dan pengujian aspal. Pengujian bahan terdiri dari:

perkerasan lentur. Oleh karena itu, diperlukan suatu material yang dapat membantu melapisi bahan agregat selain aspal agar dapat mengurangi pengaruh tersebut, contohnya bahan polimer atau plastik.

Salah satu jenis plastik yang digunakan adalah LDPE (Low Density Poly Ethylene). LDPE (Low Density Poly Ethylene) merupakan jenis plastik Poly Ethylene yang bersifat lembut, fleksibel dan mudah didapat. Plastik jenis LDPE (Low Density Poly Ethylene) biasa digunakan sebagai plastik jernih pembungkus makanan dan minuman.

Nilai stabilitas pada campuran aspal cenderung meningkat apabila campuran lapis aspal beton atau laston diselimuti dengan limbah plastik LDPE [1]. Pada aspal lapis beton atau laston terdapat 3 lapis, salah satunya yaitu Asphalt Concrete - Binder Course (ACBC) sebagai bahan pengikat. Umumnya laston AC-BC digunakan untuk jalan-jalan dengan beban lalu lintas yang cukup berat. Laston AC-BC berfungsi mengurangi tegangan/ regangan akibat beban lalu-lintas dan [2]

meneruskannya ke lapis di bawahnya. Jadi, pada laston AC-BC harus mempunyai ketebalan dan kekakuan yang cukup.

Oleh karena itu, dalam penelitian ini akan dilakukan modifikasi pengaruh penambahan plastik Low Density Poly Ethylene (LDPE) sebagai bahan tambahan dalam campuran lapis aspal beton AC-BC (Asphalt Concrete- 1. Nilai Rongga dalam campuran (VIM)

Binder Course). Yang bertujuan untuk meningkatkan 2. Nilai Rongga dalam agregat (VMA)

sifat-sifat fisik campuran laston dan karakteristiknya, 3. Nilai Rongga terisi Aspal (VFB)

serta meningkatkan nilai fungsi limbah plastik sebagai 4. Nilai Kadar aspal optimum wujud kepedulian terhadap lingkungan.

\section{Metode Penelitian}

Langkah - langkah pelaksanaan penelitian untuk mendapatkan hasil dalam Proyek Akhir ini adalah 2.7 Kesimpulan dan Saran sebagai berikut :

\subsection{Studi Pustaka}

Kegiatan ini adalah mengumpulkan materi dan mempelajari referensi yang mendukung dalam penyusunan proyek akhir. Studi literatur ini dilakukan mulai tahap awal sampai akhir.

\subsection{Persiapan Alat dan Bahan}

Material agregat kasar dan halus yang digunakan dalam penelitian ini berasal dari daerah Tegalsari, Banyuwangi, dan bahan pengisi (filler). Untuk material plastik LDPE diperoleh dari tempat pengempul plastik di daerah Rogojampi. Sedangkan material aspal 60/70 diperoleh dari setempat.
1. Pengujian Aspal

2. Pengujian Agregat

3. Pengujian Plastik LDPE

\subsection{Pembuatan Benda Uji}

Pembutan benda uji dilakukan menggunakan plastik $0 \%, 2 \%, 3 \%$, dan 4\%. Variasi kadar aspal dibuat 3 benda uji pada masing-masing kadar aspal, karena dibuat perbandingan. Apabila yang memenuhi spesifikasi 2 benda uji dan 1 benda uji tidak lolos, maka benda uji tersebut dinyatakan lolos.

\subsection{Pengujian Marshall}

Pengujian Marshall dilakukan untuk mendapatkan suatu campuran aspal yang memenuhi ketentuan-ketentuan yang telah ditetapkan di dalam kriterian perencanaan. ini meliputi pengukuran stabilitas dan alir (flow) dari suatu campuran aspal dengan agregat ukuran 2,54 cm. Pengujian Marshall mengacu pada 2.6 Analis Data dan Pembahasan

Setelah semua data pengujian yang diperlukan terkumpul, selanjutnya akan dilakukan analisisa dari data tersebut. Pembahasan hasil analisa mencakup beberapa hal antara lain :

5. Nilai Stabilitas

6. Nilai Kelelehan (Flow)

7. Nilai Marshall Quoetien

Langkah terakhir setelah semua proses analisa dan pembahasan selesai, maka di lakukan pembuat kesimpulan. Pada bab ini berisi tentang kesimpulan dari hasil pengujian yang telah di lakukan dan saran yang sekiranya ada hal - hal yang tidak sesuai dengan spesifikasi yang ada. jenis LDPE. Variasi kadar plastik yang digunakan yaitu 


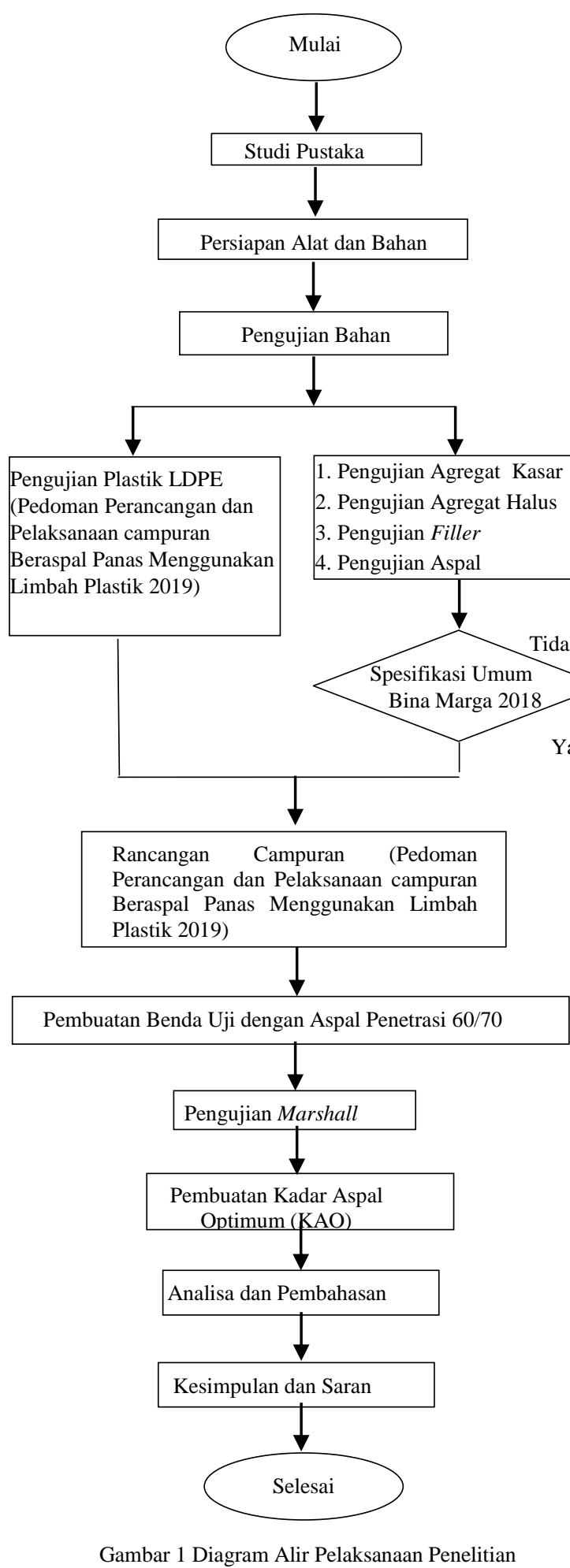

Panas Menggunakan Limbah Plastik 2019. Semua pengujian agregat telah memenuhi spesifikasi yang ditentukan.

\subsection{Pengujian Aspal Pen 60/70}

Pengujian aspal pen.60/70 dilakukan untuk melihat kelayakan aspal yang akan digunakan dalam pembuatan benda uji telah memenuhi Spesifikasi Perancangan dan Pelaksanaan Campuran Beraspal Panas Menggunakan Limbah Plastik (2019). Aspal yang digunakan berupa aspal penetrasi 60/70. Pengujian aspal yang dilakukan meliputi pengujian berat jenis aspal, titik lembek aspal, daktulitas aspal, titik nyala dan titik bakar aspal.

\subsection{Pengujian Plastik}

Pengujian plastik yang dilakukan yaitu pengujian Kadar air dan telah memenuhi Spesifikasi Perancangan dan Pelaksanaan Campuran Beraspal Panas Menggunakan Limbah Plastik (2019).

\subsection{Hasil Pengujian Marshall}

1. Hasil Uji Marshall Plastik LDPE 0\%

Hasil pengujian Marshall pada plastik LDPE 0\% dapat dilihat pada Tabel 1.

Tabel 1. Hasil Uji Marshall Plastik LDPE 0\%

\begin{tabular}{lllllll}
\hline $\begin{array}{l}\text { Variasi } \\
\text { Kadar } \\
\text { Aspal }\end{array}$ & Stabilitas & Flow & $\begin{array}{l}\text { Marshall } \\
\text { Quotient }\end{array}$ & VFB & VIM & VMA \\
\cline { 2 - 7 } & $(\mathrm{Kg})$ & $(\mathrm{mm})$ & $(\mathrm{Kg} / \mathrm{mm})$ & $(\%)$ & $(\%)$ & $(\%)$ \\
\hline $4,5 \%$ & 1226,30 & 2,83 & 423,90 & 65,19 & 8,55 & 16,45 \\
$5,0 \%$ & 1289,30 & 2,78 & 396,40 & 66,73 & 5,00 & 15,89 \\
$5,5 \%$ & 1437,50 & 3,08 & 394,00 & 70,10 & 5,60 & 16,08 \\
$6,0 \%$ & 1378,20 & 3,32 & 326,00 & 73,73 & 8,54 & 19,81 \\
$6,5 \%$ & 1482,00 & 3,11 & 397,80 & 75,89 & 4,93 & 20,38 \\
\hline Spesifikasi & $>900$ & $2-4$ & $>250$ & $>65$ & $3-5$ & $>15$ \\
BM 2018 & & & & & & \\
\hline
\end{tabular}

2. Hasil Uji Marshall Plastik LDPE 2\%

Hasil pengujian Marshall pada plastik LDPE 0\% dapat dilihat pada Tabel 1.

Tabel 2. Hasil Uji Marshall Plastik LDPE 2\%

\begin{tabular}{lllllll}
\hline $\begin{array}{l}\text { Variasi } \\
\text { Kadar }\end{array}$ & Stabilitas & Flow & $\begin{array}{l}\text { Marshall } \\
\text { Quotient }\end{array}$ & VFB & VIM & VMA \\
\cline { 2 - 7 } & $(\mathrm{Kg})$ & $(\mathrm{mm})$ & $(\mathrm{Kg} / \mathrm{mm})$ & $(\%)$ & $(\%)$ & $(\%)$ \\
\hline $4,5 \%$ & 1622,80 & 3,00 & 467,90 & 52,25 & 7,56 & 15,54 \\
$5,0 \%$ & 1611,60 & 3,61 & 427,20 & 65,73 & 4,99 & 15,17 \\
$5,5 \%$ & 1526,40 & 3,88 & 449,00 & 69,90 & 4,87 & 15,42 \\
$6,0 \%$ & 1430,10 & 3,80 & 377,30 & 70,11 & 8,34 & 19,64 \\
$6,5 \%$ & 1593,10 & 3,43 & 436,20 & 72,79 & 4,84 & 17,82 \\
\hline Spesifikasi & $>900$ & $2-4$ & $>250$ & $>65$ & $3-5$ & $>15$ \\
BM 2018 & & & & & & \\
\hline
\end{tabular}

\subsection{Pengujian Agregat}

Pengujian agregat dan filler yang dilakukan meliputi pengujian gradasi analisa saringan, lolos ayakan No.200, berat jenis dan penyerapan air, impact test, dan keausan menggunakan mesin los angeles. Dengan menggunakan

3. Hasil Uji Marshall Plastik LDPE 3\%

Hasil pengujian Marshall pada plastik LDPE 3\% dapat dilihat pada Tabel 1. acuan Spesifikasi Bina Marga 2018 dan Spesifikasi Perancangan dan Pelaksanaan Campuran Beraspal 


\begin{tabular}{lllllll}
\multicolumn{7}{c}{ Tabel 3. Hasil Uji Marshall Plastik LDPE 3\% } \\
\hline $\begin{array}{l}\text { Variasi } \\
\text { Kadar } \\
\text { Aspal }\end{array}$ & Stabilitas & Flow & $\begin{array}{l}\text { Marshall } \\
\text { Quotient }\end{array}$ & VFB & VIM & VMA \\
\cline { 2 - 7 } & $(\mathrm{Kg})$ & $(\mathrm{mm})$ & $(\mathrm{Kg} / \mathrm{mm})$ & $(\%)$ & $(\%)$ & $(\%)$ \\
\hline $4,5 \%$ & 1685,20 & 3,64 & 506,30 & 51,68 & 7,48 & 15,47 \\
$5,0 \%$ & 1604,20 & 4,07 & 464,20 & 62,18 & 4,97 & 14,36 \\
$5,5 \%$ & 1652,60 & 3,88 & 463,20 & 69,10 & 4,84 & 15,40 \\
$6,0 \%$ & 1752,40 & 4,24 & 432,20 & 57,90 & 7,90 & 16,17 \\
$6,5 \%$ & 1878,40 & 3,81 & 472,50 & 72,55 & 4,29 & 17,74 \\
\hline $\begin{array}{l}\text { Spesifikasi } \\
\text { BM 2018 }\end{array}$ & $>900$ & $2-4$ & $>250$ & $>65$ & $3-5$ & $>15$ \\
& & & & & & \\
\hline
\end{tabular}

4. Hasil Uji Marshall Plastik LDPE 4\%

Hasil pengujian Marshall pada plastik LDPE $4 \%$ dapat dilihat pada Tabel 1 .

\begin{tabular}{lllllll}
\multicolumn{7}{c}{ Tabel 4. Hasil Uji Marshall Plastik LDPE 4\% } \\
\hline $\begin{array}{l}\text { Variasi } \\
\text { Kadar } \\
\text { Aspal }\end{array}$ & Stabilitas & Flow & $\begin{array}{l}\text { Marshall } \\
\text { Quotient }\end{array}$ & VFB & VIM & VMA \\
\cline { 2 - 7 } & $(\mathrm{Kg})$ & $(\mathrm{mm})$ & $(\mathrm{Kg} / \mathrm{mm})$ & $(\%)$ & $(\%)$ & $(\%)$ \\
\hline $4,5 \%$ & 1778,40 & 3,71 & 577,30 & 48,01 & 6,69 & 12,76 \\
$5,0 \%$ & 1837,60 & 4,14 & 568,40 & 58,53 & 4,52 & 14,35 \\
$5,5 \%$ & 1841,30 & 4,22 & 466,20 & 65,19 & 4,55 & 15,14 \\
$6,0 \%$ & 2052,50 & 4,27 & 483,50 & 56,94 & 5,88 & 16,08 \\
$6,5 \%$ & 2067,30 & 4,25 & 536,00 & 61,26 & 4,18 & 17,17 \\
\hline Spesifikasi & $>900$ & $2-4$ & $>250$ & $>65$ & $3-5$ & $>15$ \\
BM 2018 & & & & & &
\end{tabular}

\subsection{Rekapitulasi Hasil Pengujian Aspal}

1. Stabilitas

Stabilitas dibutuhkan untuk mengetahui seberapa besar kemampuan perkerasan untuk menahan beban lalulintas tanpa menimbulkan perubahan yang tetap, seperti gelombang, alur dan bleeding. Hasil rekapitulasi nilai stabilitas dapat dilihat pada Tabel 5.

Tabel 5. Hasil Rekapitulasi Nilai Stabilitas

\begin{tabular}{lllll}
\multirow{2}{*}{$\begin{array}{l}\text { Macam } \\
\text { Campuran }\end{array}$} & Stabilitas & Stabilitas & Stabilitas & Sstabilitas \\
\cline { 2 - 5 } & & & & \\
\hline $4,5 \%$ & 1226,30 & 1622,80 & 1685,70 & 1778,40 \\
$5,0 \%$ & 1289,30 & 1611,60 & 1604,20 & 1837,60 \\
$5,5 \%$ & 1437,50 & 1526,40 & 1652,40 & 1841,30 \\
$6,0 \%$ & 1378,20 & 1430,10 & 1752,40 & 2052,50 \\
$6,5 \%$ & 1482,00 & 1593,10 & 1878,40 & 2067,30 \\
\hline Spesifikasi & MIN. 900 & MIN. 900 & MIN. 900 & MIN. 900 \\
BM 2018 & & & & \\
\hline
\end{tabular}

Selanjutnya data pengujian tersebut dipaparkan dalam bentuk grafik yang dapat dilihat pada Gambar1.

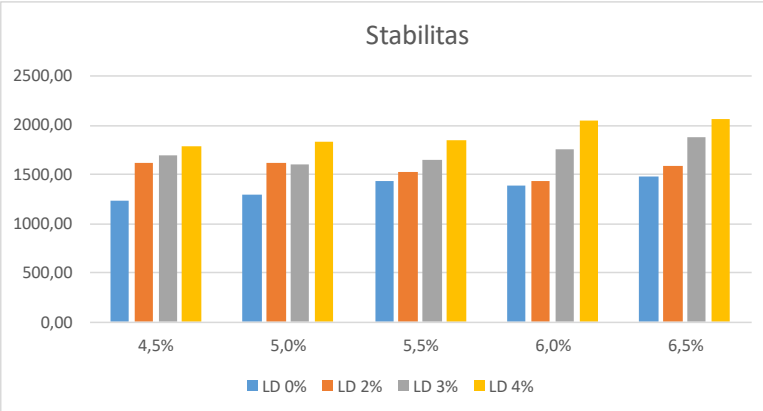

Gambar 1. Grafik Rekapitulasi Nilai Stabilitas

\section{Flow (Kelelehan)}

Nilai flow dipengaruhi oleh gradasi agregat dan proses pemadatan. Campuran aspal dengan nilai flow yang terlalu rendah cenderung menyebabkan campuran tersebut menjadi kaku dan getas sedangkan campuran beraspal panas dengan flow yang terlalu tinggi cenderung bersifat plastis atau mudah mengalami perubahan bentuk akibat beban lalu lintas yang tinggi. Hasil rekapitulasu nilai flow dapat dilihat pada Tabel 6 .

Tabel 6. Hasil Rekapitulasi Nilai Flow

\begin{tabular}{lllll}
\hline \multirow{2}{*}{$\begin{array}{l}\text { Cacam } \\
\text { Campuran }\end{array}$} & Flow & Flow & Flow & Flow \\
\cline { 2 - 5 } & LD 0\% & LD 2\% & LD 3\% & LD 4\% \\
\hline $4,5 \%$ & 2,83 & 3,00 & 3,64 & 3,71 \\
$5,0 \%$ & 2,78 & 3,61 & 4,07 & 4,14 \\
$5,5 \%$ & 3,08 & 3,57 & 3,88 & 4,22 \\
$6,0 \%$ & 3,32 & 3,80 & 4,24 & 4,27 \\
$6,5 \%$ & 3,11 & 3,43 & 3,81 & 4,25 \\
\hline Spesifikasi & $2-4$ & $2-4$ & $2-4$ & $2-4$ \\
BM 2018 & & & & \\
\hline
\end{tabular}

Selanjutnya data pengujian tersebut dipaparkan dalam bentuk grafik yang dapat dilihat pada Gambar 2.

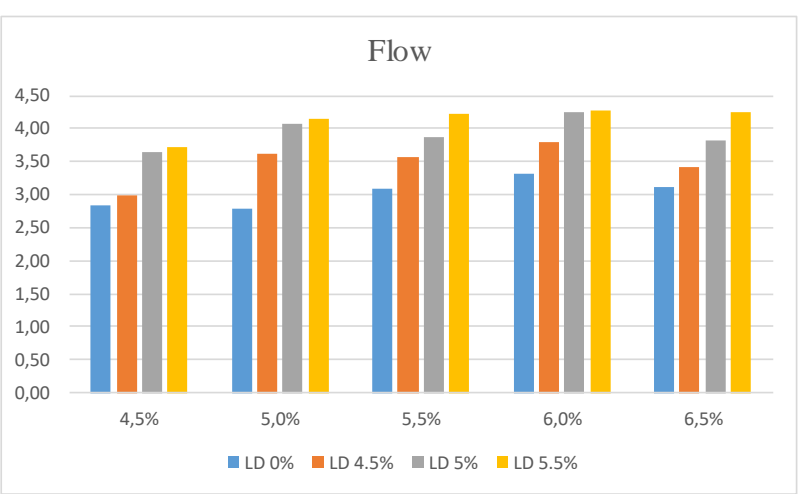

Gambar 2. Grafik Rekapitulasi Nilai Flow

\section{Marshall Quotient (MQ)}

Nilai Marshall Quotient $(M Q)$ merupakan indeks kelenturan suatu campuran berupa perbandingan antara stabilitas terhadap flow dengan satuan $\mathrm{kg} / \mathrm{mm}$. Nilai $M Q$ ini dihubungkan dengan daya tahan perkerasan terhadap deformasi. Semakin

Journal of Applied Civil Engineering and Infrastructure (JACEIT) 
besar nilai $M Q$ menandakan campuran semakin $\mathrm{kaku}$ /getas sehingga dapat terjadi retak apabila diberi beban, sedangkan semakin kecil nilai MQ menandakan campuran semakin lentur dan mampu berdeformasi apabila diberi beban. Hasil rekapitulasi nilai Marshall Quotient dapat dilihat pada Tabel 7.

Tabel 7. Hasil Rekapitulasi Nilai $M Q$

\begin{tabular}{lllll}
\hline \multirow{2}{*}{$\begin{array}{l}\text { Macam } \\
\text { Campuran }\end{array}$} & $\boldsymbol{M Q}$ & $\boldsymbol{M Q}$ & $\boldsymbol{M Q}$ & $\boldsymbol{M Q}$ \\
\cline { 2 - 5 } & LD 0\% & LD 2\% & LD 3\% & LD 4\% \\
\hline $4,5 \%$ & 423,9 & 467,90 & 506,30 & 577,30 \\
$5,0 \%$ & 396,4 & 427,20 & 464,20 & 568,40 \\
$5,5 \%$ & 394,0 & 449,00 & 463,20 & 466,20 \\
$6,0 \%$ & 326,0 & 377,30 & 432,20 & 483,50 \\
$6,5 \%$ & 397,8 & 436,20 & 472,50 & 536,00 \\
\hline Spesifikasi & $>250$ & $>250$ & $>250$ & $>250$ \\
BM 2018 & & & & \\
\hline
\end{tabular}

Selanjutnya data pengujian tersebut dipaparkan dalam bentuk grafik yang dapat dilihat pada Gambar 3.

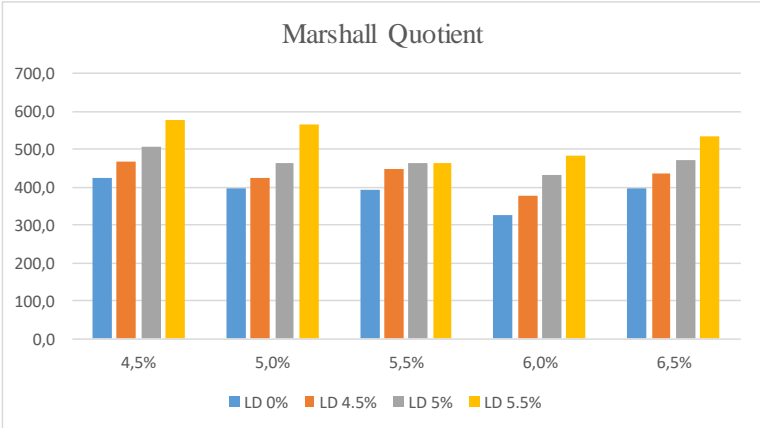

Gambar 3. Grafik Rekapitulasi Nilai $M Q$

\section{Rongga Terisi Aspal ( $V F B$ )}

Nilai $V F B$ dipengaruhi oleh jumlah dan temperature pemadatan, gradasi agregat dan kadar aspal. Nilai $V F B$ yang terlalu rendah akan mengurangi keawetan suatu campuran aspal sedangkan nilai $V F B$ yang terlalu tinggi campuran aspal mudah mengalami bleeding karena rongga dalam campuran tidak tersedia atau terlalu kecil yang menyebabkan aspal naik ke permukaan. Hasil rekapitulasi nilai rongga terisi aspal $(V F B)$ dapat dilihat pada Tabel 8.

Tabel 8. Hasil Rekapitulasi nilai VFB

\begin{tabular}{|c|c|c|c|c|}
\hline \multirow[t]{2}{*}{$\begin{array}{l}\text { Macam } \\
\text { Campuran }\end{array}$} & $V F A / V F B$ & $V F A / V F B$ & $V F A / V F B$ & $V F A / V F B$ \\
\hline & LD $0 \%$ & LD $2 \%$ & LD 3\% & LD $4 \%$ \\
\hline $4,5 \%$ & 65,19 & 52,25 & 51,68 & 48,01 \\
\hline $5,0 \%$ & 66,73 & 65,34 & 62,18 & 58,53 \\
\hline $5,5 \%$ & 70,10 & 69,90 & 69,10 & 65,19 \\
\hline $6,0 \%$ & 73,73 & 70,11 & 57,90 & 56,94 \\
\hline $6,5 \%$ & 75,89 & 72,79 & 72,55 & 61,26 \\
\hline $\begin{array}{l}\text { Spesifikasi } \\
\text { BM } 2018 \\
\end{array}$ & MIN 65 & MIN 65 & MIN 65 & MIN 65 \\
\hline
\end{tabular}

Selanjutnya data pengujian tersebut dipaparkan dalam bentuk grafik yang dapat dilihat pada Gambar 4

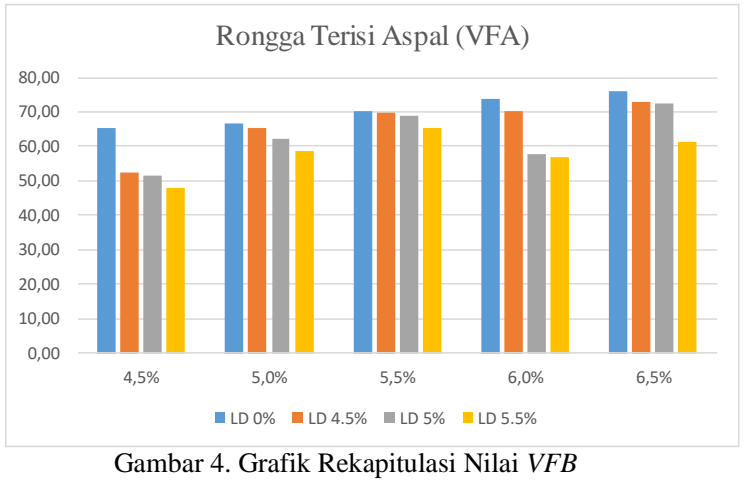

\section{Rongga Terisi Aspal VIM}

Rongga dalam campuran adalah volume total udara yang berada di antara partikel agregat yang terselimuti aspal dalam suatu campuran yang telah dipadatkan dan dinyatakan dalam persen volume bulk. Nilai VIM dipengaruhi oleh gradasi agrgegat, jumlah dan temperature pemadatan. Hasil rekapitulasi nilai rongga dalam campuran (VIM) dapat dilihat pada Tabel 9.

\begin{tabular}{lllll}
\multicolumn{5}{c}{ Tabel 9. Hasil Rekapitulasi nilai VIM } \\
\hline $\begin{array}{l}\text { Macam } \\
\text { Campuran }\end{array}$ & $\boldsymbol{V I M}$ & $\boldsymbol{V I M}$ & $\boldsymbol{V I M}$ & $\boldsymbol{V I M}$ \\
\cline { 2 - 5 } & LD 0\% & LD 2\% & LD 3\% & LD 4\% \\
\hline $4,5 \%$ & 8,55 & 7,56 & 7,48 & 6,69 \\
$5,0 \%$ & 5,00 & 4,99 & 4,97 & 4,52 \\
$5,5 \%$ & 5,60 & 4,87 & 4,84 & 4,55 \\
$6,0 \%$ & 8,54 & 8,34 & 7,90 & 5,88 \\
$6,5 \%$ & 4,93 & 4,84 & 4,29 & 4,18 \\
\hline Spesifikasi & $3-5$ & $3-5$ & $3-5$ & $3-5$ \\
BM 2018 & & & & \\
\hline
\end{tabular}

Selanjutnya data pengujian tersebut dipaparkan dalam bentuk grafik yang dapat dilihat pada Gambar 5.

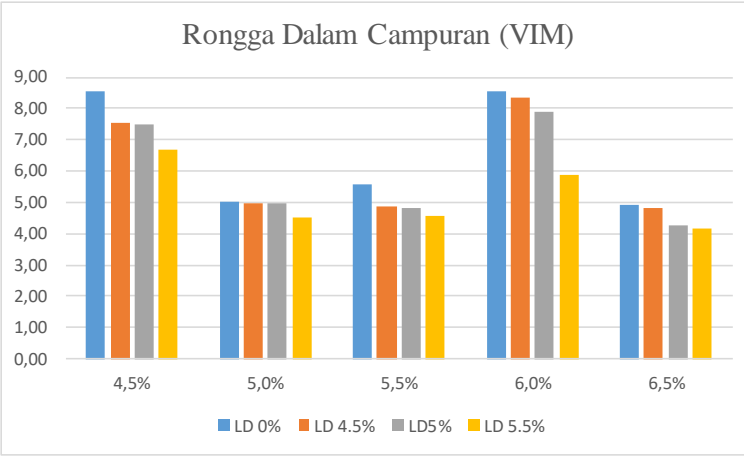

Gambar 5. Grafik Rekapitulasi Nilai $V F B$

\section{Rongga Dalam Agregat (VMA)}

Rongga dalam agregat adalah rongga antar butiran agregat dalam campuran aspal yang sudah dipadatkan serta aspal efektif yang dinyatakan dalam prosentase volume total campuran. Nilai VMA dipengaruhi oleh faktor pemadatan yaitu jumlah tumbukan dan temperature pemadatan. 
Hasil rekapitulasi nilai rongga dalam agregat (VMA) dapat dilihat pada Tabel 10.

\begin{tabular}{|c|c|c|c|c|}
\hline \multicolumn{5}{|c|}{ Tabel 10. Hasil Rekapitulasi nilai $V M A$} \\
\hline Macam & $V M A$ & $V M A$ & $V M A$ & $V M A$ \\
\hline & LD 0\% & LD $2 \%$ & LD 3\% & $\mathrm{LD} 4 \%$ \\
\hline $4,5 \%$ & 16,45 & 15,54 & 15,47 & 12,76 \\
\hline $5,0 \%$ & 15,89 & 15,17 & 14,36 & 14,35 \\
\hline $5,5 \%$ & 16,08 & 15,42 & 15,40 & 15,14 \\
\hline $6,0 \%$ & 19,81 & 19,64 & 16,17 & 16,08 \\
\hline $6,5 \%$ & 20,38 & 17,82 & 17,74 & 17,17 \\
\hline $\begin{array}{l}\text { Spesifikasi } \\
\text { BM } 2018\end{array}$ & $>15$ & $>15$ & $>15$ & $>15$ \\
\hline
\end{tabular}

Selanjutnya data pengujian tersebut dipaparkan dalam bentuk grafik yang dapat dilihat pada Gambar 6.

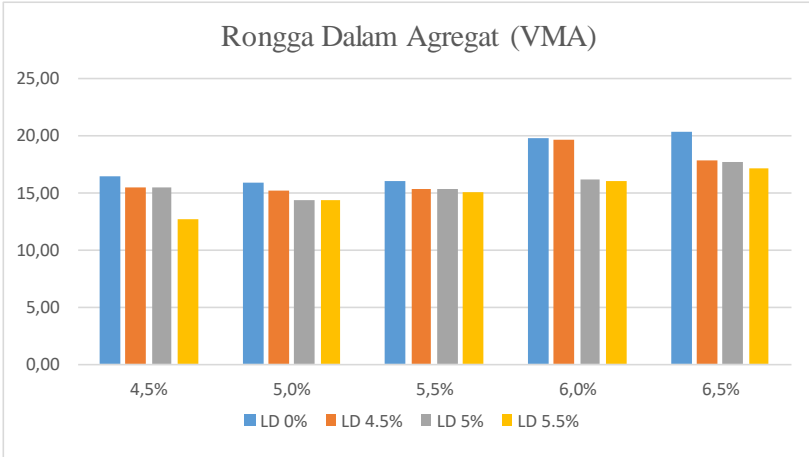

Gambar 6. Grafik Rekapitulasi Nilai VMA

\subsection{Kadar Aspal Optimum (KAO)}

Penentuan kadar aspal optimum (KAO) bertujuan untuk mengetahui kadar aspal yang baik atau kadar aspal efektif pada campuran lapis aspal beton. Dari masingmasing grafik hubungan antara parameter pengujian Marshall dengan variasi kadar aspal 4,5\%, 5,0\%, 5,5\%, $6,0 \%$ dan $6,5 \%$ diperoleh nilai kadar aspal optimum pada setiap grafik hasil pengujian. Hasil pengujian Marshall pada kadar plastik LDPE 0\%, 2\%, 3\% dan 4\% kemudian dihubungkan dalam diagram batang yang dapat dilihat pada Tabel 11.

Tabel 11. Pententuan Kadar Aspal Optimum (KAO)

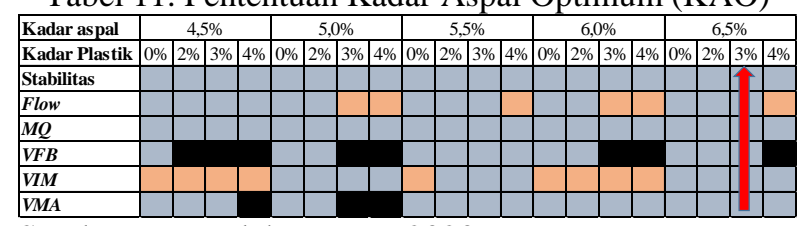

Sumber : Pengolahan Data, 2020

Keterangan :

: Nilai sesuai spesifikasi

: Nilai di atas spesifikasi
: Nilai di bawah spesifikasi

: Nilai Aspal Optimum (KAO)

\section{Kesimpulan}

Berdasarkan penelitian terhadap penambahan plastik LDPE sebagai bahan tambah agregat pada campuran laston AC-BC diperoleh beberapa kesimpulan sebagai berikut :

1. Semakin bertambahnya kadar plastik yang digunakan nilai stabilitas semakin tinggi. Semakin tinggi nilai stabilitas mengakibatkan campuran menjadi semakin keras atau mudah retak.

2. Semakin bertambahnya kadar plastik yang digunakan nilai flow semakin tinggi. nilai flow meningkat karena semakin tinggi kadar plastik menyebabkan campuran menjadi semakin elastis.

3. Semakin bertambahnya kadar plastik LDPE yang digunakan, nilai VIM dan VMA yang dihasilkan semakin rendah. Hal ini disebabkan plastik dapat menutupi pori pori agregat dan daya ikat agregat jadi semakin kuat. Maka, dapat ditarik kesimpulan bahwa variasi plastik LDPE berpengaruh terhadap nilai VIM dan VMA yang dihasilkan.

4. Semakin bertambahnya kadar plastik, nilai VFA/VFB yang dihasilkan semakin rendah. Hal ini mengakibatkan campuran kurang kedap terhadap air dan udara yang akhirnya lapis menyebabkan lapis perkerasan tidak tahan lama. Jadi, dapat disimpulkan bahwa pengaruh penambahan plastik LDPE tidak terlalu mempengaruhi keawetan campuran.

5. Semakin bertambahnya kadar plastik, nilai MQ yang dihasilkan semakin tinggi. Semakin tinggi nilai MQ mengindikasikan semakin tinggi kekakuan suatu campuran dan campuran semakin rentan terhadap keretakan.

6. Pada penelitian ini diperoleh nilai KAO pada kadar aspal 6,5\% dengan kadar plastik 3\% dan nilai stabilitas $1878,40 \mathrm{~kg}$.

\section{Ucapan Terimakasih}

Terima kasih saya ucapkan kepada orang tua tercinta, segenap pimpinan Jurusan Teknik Sipil Politeknik Negeri Banyuwangi, dosen pembimbing, serta temanteman yang telah memberikan bantuan dan dukungan.

\section{Daftar Rujukan}

[1] Jonathan, C. (2017). Karakteristik Aspal Beton Menggunakan Agregat Terselimuti Limbah Plastik Low density Polyethylene (LDPE). Jakarta: Universitas Tarumanegara.

[2] SNI 06-2456-1991. (1991). Metode Pengujian Penetrasi BahanBahan Bitumen. Badan Standardisasi Nasional: Jakarta. 